AperTO - Archivio Istituzionale Open Access dell'Università di Torino

\title{
Sausage fermentation and starter cultures in the era of molecular biology methods
}

\section{This is the author's manuscript}

Original Citation:

Availability:

This version is available http://hdl.handle.net/2318/1680016

since 2021-03-10T10:01:05Z

Published version:

DOI:10.1016/j.ijfoodmicro.2018.04.038

Terms of use:

Open Access

Anyone can freely access the full text of works made available as "Open Access". Works made available under a Creative Commons license can be used according to the terms and conditions of said license. Use of all other works requires consent of the right holder (author or publisher) if not exempted from copyright protection by the applicable law. 
1 Sausage fermentation and starter cultures in the era of molecular biology methods

2

3 Irene Franciosa, Valentina Alessandria, Paola Dolci, Kalliopi Rantsiou, Luca Cocolin*

4

5 University of Torino, Dipartimento di Scienze Agrarie, Forestali e Alimentari, Largo Braccini 2,

610095 Grugliasco, Torino, Italy

7

8 *corresponding author: phone +39 011 670-8553, fax +39 011 670-8549, email:

9 lucasimone.cocolin@unito.it

10 


\section{Highlights}

- Starter cultures in fermented sausages are mixtures of lactobacilli, pediococci and coagulase negative $\operatorname{cocci}$

- Their correct use guarantees improved safety and quality

- The ecology of fermented sausage is very complex and starters have to be able to compete with native microbiota

- Lactobacillus, Staphylococcus, Debaryomyces and Penicillium are the main genera involved in sausage fermentation

- Next generation sequencing approaches allow for more in depth studies of the microbial ecology and functionality during fermentation

\section{Abstract}

Fermented sausages have a long tradition originating from Europe and they constitute a significant part of the Mediterranean diet. This kind of products has a specific microbiota that is typical of the region or area where they are produced. Therefore, in order to protect the traditional aspect of these products, it is essential to understand the microbial ecology during fermentation by studying the dynamic changes that occur and to select autochthonous starter cultures that can be used in the production. In this paper we summarize the state of the art concerning the selection and use of starter cultures and ecology aspects of naturally fermented sausages. We pay particular attention to the application of bacteriocinogenic strains as they could provide an additional tool in the prevention of foodborne pathogens as well as enhancing the competitiveness of the starter organisms. Microbial ecology of fermented sausages has been determined by traditional microbiological methods, but the introduction in food microbiology of new molecular techniques complements the studies carried out so far and allows scientists to overcome the limitations of traditional methods. Next Generation Sequencing (NGS) techniques represent a change in the way microbiologists address ecology and diversity in foods. Indeed the application of metataxonomics and metagenomics will permit a detailed understanding of microbial ecology. A thorough knowledge of the mechanisms behind the biological processes will enhance meat fermentation control and modulation to obtain products with desired organoleptic properties. 
40 Keywords: Lactic Acid Bacteria; Coagulase Negative Cocci; Starter Cultures; Bioprotection; Ecology;

41 Metataxonomics; Metagenomics

42 


\section{Introduction}

In Europe, dry fermented sausages have a long tradition originating from Mediterranean countries during Roman times. Processing conditions, as well as ingredients and additives, vary among the different types of fermented sausages (Gardini et al., 2001). In fact, 'typical' foods of any region or area have their own peculiar characteristics that are deeply rooted in tradition and linked to the territory and which arise from the use of local ingredients and specific production techniques (Aquilanti et al., 2007; Casaburi et al., 2007). The production process begins with small pieces of meat and fat that are minced; salt and spices and in some cases sugar, herbs and/or other ingredients are then added. The homogenised mixture is then stuffed into casings, and undergoes fermentation and drying. European legislation, under Reg. EC 1333/2008 (and subsequent modifications), allows the use of nitrate and nitrite as preservatives, unless subject to other regulations for protected denomination of origin (PDO) products (Aquilanti et al., 2016). The qualitative characteristics of fermented sausages are known to be largely dependent on the quality of the ingredients and raw materials, the specific conditions of the processing and ripening, and the composition of the microbial population (Aquilanti et al., 2007). Pathogenic and spoilage bacteria are inhibited; consequently, the final product has an increased shelf-life (Hugas and Monfort, 1997).

Meat fermentations are complex microbial ecosystems in which bacteria, yeasts and molds coexist. Considerable microbial diversity is observed during the fermentation process and is evidenced by the presence of several species belonging to different genera, but also strains of the same species. Through fermentation, highly perishable raw materials, such as meat and fat, are transformed in microbiologically stable final products, characterized by a defined sensory profile, enhanced due to sodium chloride supplementation and to the drying process (Cocolin et al., 2011). Changes that occur during fermentation and drying influence the aroma development in fermented sausages (Flores et al., 2004).

Many typical fermented meat products are still produced with traditional technologies without selected starters. However, in the modern sausage production, the use of starter cultures is becoming more frequent to guarantee safety and to standardize product properties, for example consistent flavor and color and shorter ripening time (Cocolin et al., 2001). 


\section{Starter cultures}

Starter cultures are preparations that contain actively growing or resting forms of microorganisms that with their metabolic activity (Fig. 1) impart desired effects during fermentation (Hammes and Hertel, 1998). Industrialized production of starter cultures is a consequence of the gradual shift in sausage production from small local producers to large-scale processing plants and the increasing awareness of the risks for consumer health, in view of overall process efficiency (Magistà et al., 2017). The introduction of starter cultures has become essential in order to shorten the ripening period, ensure colour development, enhance the flavour and improve product safety, given that industrial production of fermented sausages is increasing (Lücke, 1986). In fact, a starter culture should be capable of conducting the fermentation, colonizing the product and dominating over other microorganisms from the beginning to the end of the process (Cocolin et al., 2006).

On the other hand, the use of commercially available starters, mainly constituted of lactic acid bacteria and coagulase negative cocci, may result in a loss of peculiar organoleptic characteristics found in spontaneously fermented sausages with an impoverishment of flavor and aroma. For this reason, in several European countries, the artisanal sausages that are manufactured by relying on an unknown 'factory biota' are preferred by the consumer (Samelis et al., 1994). The quality of such artisanal, spontaneously fermented sausages possess distinctive characteristics and are often superior if compared to controlled fermentations, inoculated with industrial starters. The principal differences between traditional and industrial fermented product are summarized in the table 1 .

This is due to the technology used, the properties of the raw material (Moretti et al., 2004) and the specific composition of the microbiota (Leroy et al., 2006). Nonetheless, Sunesen and Stahnke (2003) reported that sausages produced with commercial molds show more consistent flavor, taste, drying rate, and a more uniform appearance with respect to artisan ally fermented sausages.

The microbial ecology of fermented sausages has become of increasing interest over the last few decades given that different genera, species, and even strains, have been shown to significantly affect the sensory traits of fermented sausages (Rantsiou and Cocolin, 2006). Production of artisanal sausages largely depends on the skill and experience of the meat manufacturer and may be considered an art rather than a process fully based on scientific and technological understanding. Meat fermentation is, in fact, a complex biological phenomenon accelerated by the desirable action of certain microbes in the presence of a variety of 
synergistically acting or competing species. A great variability in the quality of the products is due to traditional practices and variation in the microorganisms involved in the process.

De Vuyst (2000) underlines that it is of primordial importance to investigate and analyze the influence of the environment on the performance of a starter culture before using it in a selected product.

In order to protect the traditional aspects of these products and to select autochthonous starter cultures to be used, it is essential to understand the microbial dynamics during fermentation (Rantsiou and Cocolin, 2006).

Therefore, a current quest is to develop indigenous starters that guarantee hygienic quality and improve the sensorial aspects of the product (Talon et al., 2007). It should, however, be considered that the law allows only the use of qualified presumption of safety (QPS) in the EU, or generally recognized as safe (GRAS) in the US, microorganisms in food production. In Italy, only Lactobacillus, Pediococcus, Micrococcus, Debaryomyces, and Staphylococcus xylosus, Staphylococcus simulans and Staphylococcus carnosus are authorized as starters cultures for sausage production (Gazzetta Ufficiale, 1995).

\subsection{Starter culture selection parameters}

So far the selection of a starter culture has been based on the screening of a great number of isolates in smallscale food fermentations. A satisfactory performance of the selected starter culture in the process, and an acceptable organoleptic evaluation of the food product are the fundamental characteristics to be found. The behavior of the starter culture in relation to the environmental factors and ripening conditions encountered during a specific production needs to be carefully investigated and standardized in the selection process. It is necessary to understand the properties required and the specific technology and recipe for which a strain will be used in order to develop the ideal starter culture (Hansen, 2002).

According to Holzapfel (1997), in order to improve product quality, the introduction of starter cultures in traditional small-scale fermentations should incorporate considerations as (i) rapid metabolic activities (acid production); (ii) improved and predictable fermentation processes; (iii) desirable sensory attributes; (iv) improved safety and reduced hygienic and toxicological risks. Another important factor is the interaction in mixed cultures of selected starter strains, with consideration for the behavior of these strains under defined conditions, and within the food matrix. Other aspects, which should be considered, include: (i) competitive behavior, viability and survival; (ii) antagonism against pathogens and spoilage microbes; (iv) rate of acid production; (v) organoleptic changes; (vi) primary metabolites of fermentation; (vii) degradation of 
antinutritive factors; (vii) detoxification; (viii) probiotic features (Holzapfel, 1997). Modern approaches for selection of the best strain(s) for a process integrate also technical safety and health-promoting features (Holzapfel, 2002).

It is essential to know the autochthonous microbiota of fermented food that is to be analyzed because commercial starter cultures usually originate either from substrates or from the processes in which they are applied. Factors that can contribute to the selection of microbial populations typical of a fermentation process are environmental conditions, back-slopping, adaptation and the repeated use of specific tools (Holzapfel, 1997).

\section{Ecological aspects of sausage fermentation}

Most European fermented sausages still follow the traditional procedures in which fermentation and ripening depend on the activities of heterogeneous microbial communities (Gardini et al., 2001, Cocolin et al., 2006). Two wide groups of bacteria largely predominate, lactic acid bacteria (LAB) and the group known as either coagulase-negative cocci (CNC) or (gram-positive)-catalase-positive cocci (GCC+/CPC), which includes both micrococci and coagulase-negative staphylococci (CNS) (Aquilanti et al., 2016). Yeasts and filamentous fungi also play a relevant role, through the formation of a superficial film which exerts a protective action against both excessive dehydration and the oxidation of the lipid fraction due to oxygen and light (Gardini et al., 2001, Cocolin et al., 2006). The acidification process that is the result of the fermentation of the sugars into lactic acid by LAB, plays a fundamental role to prevent spoilage and pathogen outgrowth. Coagulase-negative cocci are involved in the proteolytic and lipolytic processes thus playing a central role in the formation of the final organoleptic characteristics (Hammes and Hertel, 1998), and contributing to nitrate reduction and color formation, as well as to prevention of rancidity. In addition, the characteristic flavors and surface aspect are due to yeasts and molds (Cocolin et al., 2006). LAB are more numerous than $\mathrm{CNC}$ during fermentation and ripening, remaining more stable in the ripened products.

148 Within LAB, facultatively heterofermentative lactobacilli generally prevail and, among them, the two 149 psychrotrophic species Lactobacillus sakei and Lactobacillus curvatus are dominant. Within CNC, Staphylococcus xylosus neatly dominates (Aquilanti et al., 2016). 
151 The selection of specific populations adapted to a specific environment depends on ingredient composition,

152 fermentation and maturation factors (Rantsiou et al., 2005a). The production environment may have an 153 impact on the microbial ecology of the product. For example, Greppi et al. (2015) showed that strains 154 isolated from environmental samples were also detected either in the raw materials or in the product. This 155 finding highlights that microorganisms may enter in the production plant with the raw materials. 156 Furthermore, it underlines that the production environment is a source of continuous "inoculation", during 157 fermentation and ripening, with strains that may have important technological characteristics and influence 158 the characteristics of the final product.

\subsection{Lactic acid bacteria}

161 The term lactic acid bacteria is used to define a large and diverse group of microorganisms. LAB may be described as a group of Gram-positive, non-spore-forming cocci and rods, microaerophilic or facultative anaerobes, that they produce lactic acid as the major end-product during fermentation of carbohydrates (Halàsz, 2009).

L. sakei, L. curvatus and L. plantarum are the principal species of LAB usually found in meat and meat products, including fermented sausages made with different production process (Hugas et al., 1993; Kittisakulnam et al., 2017; Pisacane et al., 2015). L. sakei is often isolated with the higher frequency with respect to L. curvatus, although sometimes the opposite occurs, or they are found at similar levels; $L$. plantarum is generally isolated with less frequency, but even in this case exceptions are found, probably due to particular processing conditions. The same is also true for the members of other LAB genera, such as Weissella, Leuconostoc, Lactococcus, and Pediococcus since they are in general found as minority species (Aquilanti et al., 2016).

173 The genus Pediococcus, at the current time, consists of 13 species (Haakensen et al., 2009). Pediococcus 174 pentosaceus and Pediococcus acidilactici are the main species used in i) pediocin production, ii) 175 fermentation processes as a starter (co-culture) to avoid contamination, and iii) probiotic supplements for 176 animals and humans. P. pentosaceus cells are spherical arranged in tetrads. They are homofermentative, i.e. produce lactic acid as sole product of hexose fermentation (Porto et al., 2017). 
Lactobacilli and pediococci are the dominant microorganisms in sausages with a short ripening time from early stages to the end of the process: this type of product has an acid flavor with little aroma. In contrast, sausages with longer maturation times contain higher numbers of lactobacilli (Demeyer et al., 1986). Several studies have been conducted, employing molecular methods for species and strain identification, in order to understand the diversity and dynamics of LAB populations during fermented sausages production with long maturation times. Rantsiou et al. (2005a) studied the dynamics of LAB populations involved in the process of traditional fermentations performed in three countries: Hungary, Italy and Greece. In this study, 14 different species of LAB were detected. The only common species for Greek, Hungarian and Italian sausages were L. plantarum, L. curvatus and L. sakei. Furthermore, molecular characterization of the isolates revealed a country-specific geographic distribution of LAB populations... In Pisacane et al. (2015) the production of Salame Mantovano using two different types of natural casing, deriving from two different portions of the pig's intestine, was studied. Community dynamics suggested that the predominant LAB species in the two types of sausages were the same.

191 Aquilanti et al. (2016) summarized the studies concerning the structure of LAB in Mediterranean (Northern, 192 Central and Southern Italy, Greece, France, Spain and Portugal) traditional fermented sausages. Within the LAB population, facultatively heterofermentative lactobacilli generally prevailed and, among them, $L$. sakei and L. curvatus were found to be dominant in most studies. Authors underlined that there was low species variability between products of the different countries (Aquilanti et al. 2016).

\subsection{Coagulase-Negative Cocci}

Staphylococcus and Kocuria are the most representative genera of the Gram-positive Catalase-positive Cocci (GCC+) group (Morot-Bizot et al., 2006). The characteristic microbiota in sausages is composed of $S$. xylosus, S. saprophyticus and S. equorum, but many other species have been identified such as $S$. succinus, $S$. warneri, S. vitulinus, S. pasteuri, S. epidermidis, S. lentus and S. haemolyticus (Cocolin et al., 2001; Talon et al., 2011; Mainar et al., 2017). Kocuria species are ubiquitous and are highly adapted to their ecological niches (Kim et al., 2011). In fermented sausages Kocuria varians and Kocuria kristinae were mainly found (Fischer and Schleifer, 1980); moreover, K. varians is often found in biofilms (Raghupathi et al., 2016). 
Although the environmental, production plant associated microbiota, can contribute to the spoilage of the meat products, ecology of Staphylococcus occurring in the environment of spontaneously fermented sausages has not been thoroughly studied. In fact, they showed high capacity to colonize the surfaces, the equipment and the meat products (Morot-Bizot et al., 2006). Iacumin et al. (2006) studied the ecology and dynamics of staphylococci in three different local meat producers in the North East of Italy. In all three fermentations the same species of CNC (S. epidermidis, $S$. equorum, S. warneri, S. saprophyticus, S. xylosus, S. pasteuri) took part, but in variable quantity and proportions. The study evidenced that the slaughterhouse can partly influence the microbial composition of meat and a correlation between the isolated S. xylosus strains and the specific plant of production exists. This confirms the hypothesis that selection of the microbiota takes place in a production plant, depending on temperature, humidity and ingredients and influences the final sensory aspect of the product. In a comparative evaluation of the CNC communities from sausages produced in Italy, France, Greece Spain and Portugal,The dominance of S. xylosus clearly emerged, with the exception of the sausage productions in Greece and France. In fact, the CNC diversity, between different countries, was generally higher than that recorded for LAB (Aquilanti et al., 2016).

Finally, Quijada et al. (2018) analyzed five Chorizo de Leon factories in the North-West region of Castilla y Leon (Spain). The factories didn't use microbial starters and adopted similar traditional manufacturing procedures. Among the five manufactures differences in microbiota composition were observed. For the products was more evident for CNC compared to Lactobacillus species.

\subsection{Yeasts}

228 Spontaneous fermentations are usually characterised by the presence of yeasts, but studies on the yeast biodiversity in sausages are limited. Debaryomyces hansenii is the yeast species most commonly isolated according to several researches but other yeast genera have also been found, such as Candida spp. (Gardini et al., 2001). An increase in $\mathrm{pH}$ and a decrease in lactic acid content in the sausages can be caused by these yeasts that contribute to the characteristics of the final product (Gardini et al., 2001). Both D. hansenii and 
Candida utilis initially proliferate in sausages and then slowly decline (Olesen and Stahnke, 2000). C. utilis shows a considerable potential production of several volatile compounds, such as alcohols and esters which probably derive from the amino acids isoleucine, leucine, valine and phenylalanine (Olesen and Stahnke, 200). On the contrary, The primary and secondary metabolism, where lipases and proteinases are key enzymes, are the principal processes of these organisms and can produce the typical aroma of the products (Cocolin et al., 2006). A yeast can be added as aroma enhancer and can also stabilise the red colour of 239 fermented sausages (Olesen and Stahnke, 2000).

Debaryomyces spp. are extremophilic, perfect, haploid yeasts that asexually reproduce by multilateral budding, the pseudomycelium is absent, primitive or occasionally well developed. Heterogamous conjugation is the way for the sexual reproduction. In particular, D. hansenii is an osmo-, alo- and xerotolerant yeast (Breuer and Harms, 2006). Flores et al. (2004) underlined that in fermented sausages, Debaryomyces spp. can have important effects on the generation of volatile compounds during the ripening. The development of the typical aroma of the sausage was possible through the inhibition of the generation of lipid oxidation products and promoting the generation of ethyl esters. When $D$. hansenii was used as a starter it showed a positive effect on the development of flavour characteristics and stabilisation of the reddening reaction (Gardini et al., 2001).

Cocolin et al. (2006a) employed a multiphasic approach during the fermentation of a traditional sausage produced in Northern Italy. To profile the dynamics of yeast communities present during the maturation culture-dependent and independent methods were used. Through the molecular identification by PCR-DGGE and sequencing of partial 26S rRNA encoding gene of 180 isolates, D. hansenii resulted to be the dominant species throughout the fermentation process. With molecular characterization, $D$. hansenii isolates displayed a change in their population density during the maturation process of the sausages. Although the origin of the meat and the factory environment have been reported as factors that can cause variations on yeast populations in fermented meat products, most of the studies point towards D. hansenii as the most frequently and abundantly isolated yeast species (Flores et al., 2015; Mendonça et al., 2013). 


\subsection{Filamentous fungi}

260 The surface of dry-cured meat is colonized by molds able to grow on different environments and 261 substrates(Magistà et al., 2017). Xerotolerant and xerophilic fungi grow preferably in an environment with 262 low water activity $\left(\mathrm{a}_{\mathrm{w}}\right)$ and high salt concentrations as dry-cured meats. In this kind of products, fungi have also an important role in the production process because they can lead to the development of specific flavors and aromas, due to their lipolytic and proteolytic activities (Sonjak et al. 2011).

The genus Penicillium represents the major mold population of the surface mycobiota on dry-cured meat products (Sonjak et al., 2011). Penicillium is one of the most common fungi that can grow in a diverse range of habitats, from soil to vegetation to air, indoor environments and various food products (Visagie et al., 2014). Important taxonomic characters of Penicillium are the presence of conidiophore and cleistothecium (when produced). Conidiophore branching patterns have been traditionally used in the classification of Penicillium (Visagie et al., 2014). Species of Penicillium have been found in fermented meat sausages to be responsible for the surface colonization, most importantly $P$. nalgiovense and to a lesser extent, $P$. chrysogenum (López-Díaz et al., 2001). This layer of mold is important to the sausage since it has an antioxidative effect, protecting from development of the rancidity and keeping the colour; it gives the sausage its typical appearance because it allows the development of a positive microclimate at the surface for preventing, for example, sticky or slimy characteristic of the surface (Visagie et al., 2014).

\section{Bioprotection}

In fermented meat, the accumulation of particular metabolites as lactic acid, acetic acid, formic acid, ethanol, ammonium, fatty acids, hydrogen peroxide, acetaldehyde and bacteriocins can inhibit the growth of pathogenic and spoilage bacteria (Hugas and Monfort, 1997). The production of antimicrobial bacteriocins that leads to a better preservation of the product is a characteristic of particular starter cultures (Cleveland $e t$ al., 2001). Strains of all genera of LAB have been identified as bacteriocin producers. They are important in meat microbiota composition and act against bacteria closely related to the producer organisms (Lücke, 2000). However, many lactic acid bacteria (LAB) strains produce bacteriocins that are active towards pathogens or food spoilers in vitro, but not in situ, in a meat matrix (De Vuyst, 2000). 
Different bacteriocins produced by LAB strains could be applied in food products but, at the moment, only nisin and pediocin PA-1/AcH are approved for use in food preservation (Cleveland et al., 2001; Barbosa et al., 2017; Kęska et al., 2017). The application of bacteriocins in meats and meat products is allowed in three different modalities: (i) direct inoculation of bacteriocinogenic LAB strains as starter or protective cultures, (ii) direct application of bacteriocins from cell free supernatant (CFS) as food additive and (iii) incorporation of totally or partially purified bacteriocins into the packaging (Woraprayote et al., 2016). Bacteriocins improve a strain's competitiveness for the nutrients during fermentation, but without reducing the growth of the starter organisms towards the fortuitous microbiota. (Hugas and Monfort, 1997).

Many strains of Lactococcus lactis are able to produce Nisin A that has a wide antimicrobial spectrum against Gram-positive bacteria, including staphylococci, streptococci, Listeria spp., bacilli, and enterococci (Woraprayote et al., 2016). Several nisin-producing Lact. lactis strains isolated from fermented sausages showed the potential use of lactococci in this kind of products (Castellano et al., 2008).

The effect of commercial pure nisin from Lact. lactis subsp. lactis (Sigma-Aldrich) against List. monocytogenes was evaluated in Turkish fermented sausages (sucuks). All products treated with nisin, showed a reduction of List. monocytogenes population compared to the control (Hampikyan and Ugur, 2007).

L. sakei and L. curvatus strains are able to produce sakacins, bacteriocins that show high inhibitory activities towards List. monocytogenes. Sakacin Q, produced by L. curvatus ACU-1, was used by Rivas et al. (2014) for growth control of List. innocua. Cooked meat was artificially inoculated on surface during chilled storage and four different forms of bacteriocin applications were tested: protective culture, cell-free supernatant meat-borne strains of $L$. curvatus have been described as the main source of antimicrobial compounds: curvaticins. One of the isolates exhibiting inhibitory activity against List. monocytogenes ATCC 7644 was identified as L. curvatus 54M16 and studied in detail for its antimicrobial substances (Casaburi et al., 2016).

310 In the last decades, great number of L. plantarum strains that produce bacteriocins were isolated from 311 different matrices including meat (Kanatani and Oshimura, 1994). In literature, numerous small, heat-stable plantaricins have been described but not completely well characterized (Todorov, 2009). Schillinger and 
Lücke (1989) isolated, from different meat products, various bacteriocinogenic lactobacilli including $L$. plantarum. Enan et al. (1996) showed, for example, that plantaricin UG1 is produced by L. plantarum UG1 isolated from dry sausage and that this compound had no effect on Gram-negative bacteria, but a variety of Gram-positive bacteria were sensitive. An important control of List. monocytogenes growth has been obtained by application of plantaricins or L. plantarum bacteriocin producing strains (Todorov, 2009). Pediocins are biomolecules that can be synthesized by some LAB and present a broad spectrum of antimicrobial activity against Gram-positive bacteria (Papagianni and Anastasiadou, 2009), among which List. monocytogenes (Porto et al., 2017). Kingcha et al. (2012) observed a significant decrease of List. monocytogenes ATCC 19115 growth in Nhan, a Thai traditional fermented pork sausage, when it was inoculated with $P$. pentosaceus BCC 3772 cells. The antimicrobial activity was attributed to the production, by $P$. pentosaceus BCC 3772 , of pediocin that shows $100 \%$ amino acid identity with the commercial pediocin PA-1 isoform. A correlation was observed between anti-listerial activity and P. pentosaceus BCC3772 inoculum. In addition, the authors suggested that this strain is a suitable candidate for Listeria control in fermented pork sausage, given that no significant changes of Nahn's organoleptic properties were observed.

\section{Direct analysis of sausages and omics approaches}

Traditional microbiological methods, namely plate counts, isolation, and biochemical identification, have been often used for ecological studies of spontaneously fermented sausages. With this approach only easily culturable microorganisms can be detected, while the information about microorganisms that need elective methods and are applied directly in a sample (direct or culture independent approaches), have been introduced in the field of food microbiology and food fermentation, allowing scientists to overcome the limitations of classical methods (Rantsiou and Cocolin, 2006; De Filippis et al., 2018). These studies may also be able to identify sentinel microbes (essentially indicator microbes linked to various pathogens), which could be incorporated into food safety plans (Cocolin et al., 2018). The first direct or culture-independent approaches were based on fingerprinting techniques such as DGGE and have been extensively applied in 
fermented sausages ecology studies (Rantsiou and Cocolin, 2006; Aquilanti et al., 2016). In recent years however, food microbiota studies are based on sequencing (Cocolin and Ercolini, 2015). High-throughput sequencing (HTS) techniques, undoubtedly represent a step change in the way microbiologists address ecology and diversity in foods. Unlike traditional Sanger approach sequencing that could be performed on a single DNA molecule, in HTS mixed nucleic acid molecules from a complex ecosystem can be sequenced and therefore can lead to detailed profile of the microbial populations (identified as Operational Taxonomic Units, OTU) present (Cocolin et al. 2018; Zhang et al., 2017). In the mid 2000s HTS technologies became ubiquitous in microbial ecology studies; in fact, these technologies have been used to monitor the dynamics of microbial communities during fermentation of different types of foodstuffs and beverages (De Filippis et al., 2017; Fontana et al., 2016).

Metataxonomics or amplicon sequencing, is a powerful tool that allows taxonomic characterization of microbial communities, which would have been difficult if not otherwise impossible to determine using traditional microbiological techniques. For bacteria, the common amplification target is various regions of the 16S rRNA encoding gene, while for yeasts the 26S rRNA encoding gene has been used. Large sequence databases exist for these two genes (Cocolin et al., 2013). On the other hand, metagenome sequencing, or shotgun metagenome sequencing, is a technique where an entire mixed microbial community DNA is fragmented, prepared into a sequencing library and sequenced. Metagenomics offers the opportunity to look beyond the presence/absence of taxonomically defined entities (i.e. specific organisms) and instead to niche (Cocolin et al., 2017). To understand and characterize the composition and function of the microbiota in a food ecosystem the evolution of the massive sequencing technologies such as shotgun DNA-seq or RNA-seq can help (Ferrocino et al., 2018). In the field of food microbiota structure and function, the identification of enzymes, pathways and mechanisms and how these operate under specific conditions may perhaps be of superior value than determining the taxonomic composition of specific samples alone (Santiago-Rodriguez et al., 2016).

DNA is a chemically stable molecule, which can be found a long time after the death of a cell, RNA is more sensitive to degradation, especially in environments, like foods, where enzymes, such as hydrolases, are present. While DNA can give a good overview of the microorganisms that are or were present in a given 
ecosystem, it cannot provide any information on what microbes are doing regarding metabolic and spoilage activities and virulence factors expression. For this reason, if the goal of the investigation is to get an insight on how the microorganism is behaving, the RNA is a better option (Cocolin et al., 2013).

Analysis of RNA (transcriptomics), proteins (proteomics) and metabolites (metabolomics), preferably in an integrated framework, is fundamental for a full description of microbial community inasmuch metagenomic sequencing has an important limitation: it cannot directly measure the functional activity of a community under a given set of conditions (Franzosa et al., 2015).

Studies have used RT-PCR-DGGE coupled with $16 \mathrm{~S}$ rRNA-based sequencing to evaluate the diversity of metabolically active microbiota during the spontaneous fermentation of sausages (Połka et al., 2015; Rebecchi et al., 2015).

The organoleptic characteristics of the final products are influenced by volatile organic compounds (VOCs) that are produced through the breakdown of carbohydrates, proteins and lipids. Ferrocino et al. (2018) focused on studying the microbiota development and functions in an Italian fermented sausage through a shotgun DNA metagenomic approach. For the first time an integrated analysis related to volatilome profile, microbiota, gene content and consumers acceptability was presented. The study displayed the evolution of those pathways over time and condition. The most prominent differences during spontaneous and inoculated fermentation, according to the analysis, involved key genes in particular pathways: pyruvate metabolism and glycolysis. For the faster metabolic activity, confirmed by the meta-metabolomics data, in this study the sensory test showed that the presence of starter cultures had a negative impact on the properties of the product. These methods allowed to detect shifts in microbiota composition through the recognition of changes in the microbial gene content and abundance. This is important for the study of complex and dynamic microbiota of food products and for food safety both to spoilage and fraud level, especially when starter cultures are used.

\section{Conclusions}

The use of starter cultures in food fermentations, including sausages, has allowed for a greater level of safety and quality. Undoubtedly, the addition of starter strains in the meat batter for the production of sausages makes the fermentation process less prone to modifications, which are responsible for products with deviated 
396 organoleptic properties and potentially hazardous due to the presence of foodborne pathogens not inhibited 397 during the process. However, due to the traditional and artisanal aspects that fermented sausages often 398 possess, spontaneous fermentations are still used and represent a common practice especially in the 399 Mediterranean countries. Isolation and selection of new strains of well known LAB and CNC species from 400 those traditional products represents a possible alternative to the use of commercial starter cultures, which 401 nowadays are criticized since they may lead to flattened organoleptic characteristics.

402 The application of modern molecular methods, such as metataxonomics and metagenomics, in fermented 403 sausages will permit, in the near future, the understanding in detail of the microbial ecology and functions 404 and at the same time allow for a better comprehension of the interactions of the starter cultures with the meat 405 microbiota during sausage production. Only after a thorough knowledge of the mechanisms behind the 406 fermentation process in meat it will be possible its control and modulation to obtain products with desired 407 and expected organoleptic profiles. 


\section{References}

Aquilanti L., Garofalo C., Osimani A., Clementi F. (2016). Ecology of lactic acid bacteria and coagulase negative cocci in fermented dry sausages manufactured in Italy and other Mediterranean countries: an overview. International Food Research Journal 23(2), 429-445.

Aquilanti L., Santarelli S., Silvestri G., Osimani A., Petruzzelli A., Clementi F. (2007). The microbial ecology of a typical Italian salami during its natural fermentation. International Journal of Food Microbiology, 120, 136-145.

Barbosa A.A.T., Mantovani H.C., Jain S. (2017). Bacteriocins from lactic acid bacteria and their potential in the preservation of fruit products. Critical reviews in biotechnology, 37(7), 852-864.

Barbosa M.S., Todorov S.D., Ivanova I., Chobert J.-M., Haertlé T., Franco B.D. G.M. (2015). Improving safety of salami by application of bacteriocins produced by an autochthonous Lactobacillus curvatus isolate. Food Microbiol., 46, 254-262.

Breuer U., Harms H. (2006). Debaryomyces hansenii - an extremophilic yeast with biotechnological potential. Yeast, 23(6), 415-437.

Casaburi A., Aristoy M-C., Cavella S., Di Monaco R., Ercolini D., Toldra’ F., Villani F. (2007). Biochemical and sensory characteristics of traditional fermented sausages of Vallo di Diano (Southern Italy) as affected by the use of starter cultures. Meat Science, 76, 295-307.

Casaburi A., Di Martino V., Ferranti P., Picariello L., Villani F. (2016). Technological properties and bacteriocins production by Lactobacillus curvatus 54M16 and its use as starter culture for fermented sausage manufacture. Food Control, 59, 31-45.

Castellano P., Belfiore C., Fadda S., Vignolo G. (2008). A review of bacteriocinogenic lactic acid bacteria used as bioprotective cultures in fresh meat produced in Argentina. Meat Science, 79(3), 483-499.

Cleveland J., Montville T.J., Nes I.F., Chikindas M.L. (2001). Bacteriocins: safe, natural antimicrobials for food preservation. Int. J. Food. Microbiol. 71, 1-20.

Cocolin L., Alessandria V., Dolci P., Gorra R., Rantsiou K. (2013). Culture independent methods to assess the diversity and dynamics of microbiota during food fermentation. Int. J. Food Microbiol. 167, $29-43$. 
Cocolin L., Dolci P., Rantsiou K. (2011). Biodiversity and dynamics of meat fermentations: The contribution of molecular methods for a better comprehension of a complex ecosystem. Meat Science, 89, 296-302.

Cocolin L., Manzano M., Cantoni C., Comi G. (2001). Denaturing Gradient Gel Electrophoresis Analysis of the 16S rRNA Gene V1 Region To Monitor Dynamic Changes in the Bacterial Population during Fermentation of Italian Sausages. Applied and Envirnmental Microbiology, 5113-512.

Cocolin L., Mataragas M., Bourdichon F., Doulgeraki A., Pilet M.-F., Jagadeesan B., Rantsiou K., Phister T. (2018). Next generation Microbiological Risk Assessment: Meta-Omics: the next need for integration. International journal of food microbiology.

Cocolin L., Urso R., Rantsiou K., Cantoni C. and Comi G. (2006). Dynamics and characterization of yeasts during natural fermentation of Italian sausages. FEMS Yeast Research 6(5): 692-701.

De Filippis F., Parente E., Ercolini D. (2017). Metagenomics insights into food fermentations. Microbial biotechnology, 10(1), 91-102.

De Filippis F., Parente E., Ercolini D. (2018). Recent Past, Present, and Future of the Food Microbiome. Annual review of food science and technology, 9(1).

De Vuyst L. (2000). Technology aspects related to the application of functional starter cultures. Food Technology and Biotechnology, 38(2), 105-112.

Demeyer D.I., Verplaetse A., Gistelink M. (1986). Fermentation of meat: an integrated process. Belgian Journal of Food Chemistry and Biotechnology, 41, 131-140.

El Sheikha A., Montet D. (2016). Fermented foods - artisan household technology to biotechnology era. In : Montet Didier (ed.), Ray Ramesh Chandra (ed.). Fermented foods. Part I: biochemistry and biotechnology. Boca Raton : CRC Press, p. 1-15. (Food Biology Series).

Enan G.; Essaway A.A.; Uyttendaele M.; Debevere J. (1996). Antibacterial activity of Lactobacillus plantarum UG1 isolated from dry sausages: charcterization, production, and bactericidal action of plantaricin UG1. Int. J. Food Microbiol., 30: 189-215.

Ferrocino I., Bellio A., Giordano M., Macori G., Romano A., Rantsiou K., Decastelli L., Cocolin, L. (2018). Shotgun metagenomics and volatilome profile of the microbiota of fermented sausages. Applied and environmental microbiology, 84(3), e02120-17. 
Fischer U., Schleifer K. H. (1980). Vorkommen von staphylokokken un mikrokokken in Rohwurst. Fleischwirtschaft, 60, 1046-1049.

Flores M., Dura M.A., Marco A., Toldra F. (2004). Effect of Debaryomyces spp. on aroma formation and sensory quality of dry-fermented sausages. Meat Sci 68: 439-446.

Flores M., Corral S., Cano-García L., Salvador A., Belloch C. (2015). Yeast strains as potential aroma enhancers in dry fermented sausages. International journal of food microbiology, 212, 16-24.

Fontana C., Bassi D., López C., Pisacane V., Otero M.C., Puglisi E., Rebecchi A., Cocconcelli P.S., Vignolo, G. (2016). Microbial ecology involved in the ripening of naturally fermented llama meat sausages. A focus on lactobacilli diversity. International journal of food microbiology, 236, 17-25.

Franzosa E.A., Hsu T., Sirota-Madi A., Shafquat A., Abu-Ali G., Morgan X.C., Huttenhower C. (2015). Sequencing and beyond: integrating molecular 'omics' for microbial community profiling. Nature Reviews Microbiology, 13(6), 360-372.

Gardini F., Suzzi G., Lombardi A., Galgano F., Crudele M. A., Andrighetto C., Schirone M., Tofalo R. (2001). A survey of yeasts in traditional sausages of southern Italy. FEMS Yeast Research 1(2), 161167.

Gazzetta Ufficiale, Serie Generale, N. 89 del 15/4/1995

Greppi A., Ferrocino I., La Storia A., Rantsiou K., Ercolini D., Cocolin L. (2015). Monitoring of the microbiota of fermented sausages by culture independent rRNA-based approaches. International journal of food microbiology, 212, 67-75.

Haakensen M., Dobson C.M., Hill J.E., Ziola B. (2009). Reclassification of Pediococcus dextrinicus (Coster and White 1964) Back 1978 (Approved Lists 1980) as Lactobacillus dextrinicus comb. nov., and emended description of the genus Lactobacillus. International journal of systematic and evolutionary microbiology, 59(3), 615-621.

Halász A. (2009). Lactic acid bacteria. Food Quality and Standards, 3, 70-82.

Hammes W.P., Hertel C. (1998). New developments in meat starter cultures. Meat Sci 49: S125-S138.

Hampikyan H., Ugur M. (2007). The effect of nisin on L. monocytogenes in Turkish fermented sausages (sucuks). Meat science, 76(2), 327-332. 
Hansen E. B. (2002). Commercial bacterial starter cultures for fermented foods of the future. International Journal of Food Microbiology, 78, 119-131.

Holzapfel W.H. (1997). Use of starter cultures in fermentation on a household scale. Food control, 8 (56), 241-258.

Holzapfel W.H. (2002). Appropriate starter culture technologies for small-scale fermentation in developing countries. International journal of food microbiology, 75(3), 197-212.

Hugas M., Garriga M., Aymerich T., Monfort J.M. (1993). Biochemical characterization of lactobacilli from dry fermented sausages. International Journal of Food Microbiology, 18, 107-113.

Hugas M., Monfort J.M. (1997). Bacterial starter cultures for meat fermentation. Food Chemistry, 59, No. $4,547-554$.

Iacumin L., Comi G., Cantoni C., Cocolin L. (2006). Ecology and dynamics of coagulase-negative cocci isolated from naturally fermented Italian sausages. Systematic and applied microbiology, 29(6), 480486.

Justé A., Thomma B.P.H. J., Lievens B. (2008). Recent advances in molecular techniques to study microbial communities in food-associated matrices and processes. Food Microbiology, 25(6), 745761.

Kanatani K., Oshimura M. (1994). Plasmid-associated bacteriocin production by a Lactobacillus plantarum strain. Bioscience, biotechnology, and biochemistry, 58(11), 2084-2086.

Kęska P., Stadnik J., Zielińska D., Kołożyn-Krajewska D. (2017). Potential of bacteriocins from lab to improve microbial quality of dry-cured and fermented meat products. Acta Scientiarum Polonorum Technologia Alimentaria, 16(2), 119-126.

Kim W.J., Kim Y.O., Kim D.S., Choi S.H., Kim D.W., Lee J.S., Kong H.J., Nam B.H., Kim B.S., Lee S.J., Park H.S., Chae S.H. (2011). Draft genome sequence of Kocuria rhizophila 7-4. J Bacteriol $193: 4286-4287$.

Kingcha Y., Tosukhowong A., Zendo T., Roytrakuls S., Luxananil P., Chareonpornsook K., Valyasevi R., Jang S., Lee J., Jung U., Choi H.S., Suh H.J. (2012). Anti-Listeria activity of Pediococcus pentosaceus BCC 3772 and application as starter culture for Nham, a traditional fermented pork sausage. Food Control 25, 190-196. 
Kittisakulnam S., Saetae D., Suntornsuk W. (2017). Antioxidant and antibacterial activities of spices traditionally used in fermented meat products. Journal of Food Processing and Preservation, 41(4).

Leroy F., De Vuyst L. (2004). Lactic acid bacteria as functional starter cultures for the food fermentation industry. Trends in Food Science and Technology, 15(2), 67-78.

Leroy F., Verluyten J., De Vuyst L. (2006). Functional meat starter cultures for improved sausage fermentation. International Journal of Food Microbiology 106, 270-285.

López-Díaz T.M., Santos J.A., García-López M.L., Otero A. (2001). Surface mycoflora of a Spanish fermented meat sausage and toxigenicity of Penicillium isolates. International Journal of Food Microbiology, 68(1), 69-74.

Lücke F.K. (1986). Microbiological processes in the manufacture of dry sausage and raw ham. Fleischwirtschaft 66, 1505-1509.

Lücke F.K. (2000). Utilization of microbes to process and preserve meat. Meat Science, 56(2), 105-115.

Magistà D., Susca A., Ferrara M., Logrieco A.F., Perrone G. (2017). Penicillium species: crossroad between quality and safety of cured meat production. Current Opinion in Food Science, 17, 36-40.

Mainar M.S., Stavropoulou D.A., Leroy F. (2017). Exploring the metabolic heterogeneity of coagulasenegative staphylococci to improve the quality and safety of fermented meats: a review. International journal of food microbiology, 247, 24-37.

Mendonça R.C., Gouvêa D.M., Hungaro H.M., Sodré A.D.F., Querol-Simon A. (2013). Dynamics of the yeast flora in artisanal country style and industrial dry cured sausage (yeast in fermented sausage). Food control, 29(1), 143-148.

Moretti V.A., Madoni, G., Diaferi, C., Mentast, T., Palear, M.A., Panser, S., Pirone G., Gandini G., 2004. Chemical and microbiological parameters and sensory attributes of a typical Sicilian salami ripened in different conditions. Meat Science 66, 845-854.

Morot-Bizot S.C., Leroy S., Talon R. (2006). Staphylococcal community of a small unit manufacturing traditional dry fermented sausages. International journal of food microbiology, 108(2), 210-217.

Olesen P.T., Stahnke L.H. (2000). The influence of Debaryomyces hansenii and Candida utilis on the aroma formation in garlic spiced fermented sausages and model minces. Meat Science, 56(4), 357368. 
Papagianni M., Anastasiadou S. (2009). Pediocins: The bacteriocins of Pediococci. Sources, production, properties and applications. Microbial Cell Factories, 8(1), 3.

Pisacane V., Callegari M. L., Puglisi E., Dallolio G., Rebecchi A. (2015). Microbial analyses of traditional Italian salami reveal microorganisms transfer from the natural casing to the meat matrix. International journal of food microbiology, 207, 57-65.

Połka J., Rebecchi A., Pisacane V., Morelli L., Puglisi E. (2015). Bacterial diversity in typical Italian salami at different ripening stages as revealed by high-throughput sequencing of $16 \mathrm{~S}$ rRNA amplicons. Food microbiology, 46, 342-356.

Porto M.C.W., Kuniyoshi T.M., de Azevedo P.O.D.S., Vitolo M., de Souza Oliveira R.P. (2017). Pediococcus spp.: An important genus of lactic acid bacteria and pediocin producers. Biotechnology Advances. Biotechnology advances, 35(3), 361-374.

Quijada N.M., De Filippis F., Sanz J.J., del Camino García-Fernández M., Rodríguez-Lázaro D., Ercolini D., Hernández M. (2018). Different Lactobacillus populations dominate in "Chorizo de León" manufacturing performed in different production plants. Food microbiology, 70, 94-102.

Raghupathi P.K., Herschend J., Røder H.L., Sørensen S.J., Burmølle M. (2016). Genome sequence of Kocuria varians G6 isolated from a slaughterhouse in Denmark. Genome announcements, 4(2), e00076-16.

Rantsiou K., Cocolin L. (2006). New developments in the study of the microbiota of naturally fermented sausages as determined by molecular methods: a review. International Journal of Food Microbiology, $108,255-267$.

Rantsiou K., Drosinos E. H., Gialitaki M., Urso R., Krommer J., Gasparik-Reichardt J., Tóth S., Metaxopoulos I., Comi G., Cocolin L. (2005a). Molecular characterization of Lactobacillus species isolated from naturally fermented sausages produced in Greece, Hungary and Italy. Food Microbiology, 22(1), 19-28.

Rantsiou K., Urso R., Iacumin L., Cantoni C., Cattaneo P., Comi G., Cocolin L. (2005b). Culturedependent and-independent methods to investigate the microbial ecology of Italian fermented sausages. Applied and Environmental Microbiology, 71(4), 1977-1986. 
Rebecchi A., Pisacane V., Miragoli F., Polka J., Falasconi I., Morelli L., Puglisi E. (2015). Highthroughput assessment of bacterial ecology in hog, cow and ovine casings used in sausages production. International journal of food microbiology, 212, 49-59.

Rivas F.P., Castro M.P., Vallejo M., Marguet E., Campos C.A. (2014). Sakacin Q produced by Lactobacillus curvatus ACU-1: functionality characterization and antilisterial activity on cooked meat surface. Meat science, 97(4), 475-479.

Samelis J., Stavropoulos S., Kakouri A., Metaxopoulos J. (1994). Quantification and characterization of 460.

Santiago-Rodriguez T. M., Cano R., Jiménez-Flores R. (2016). Potential applications of metagenomics to assess the biological effects of food structure and function. Food \& function, 7(10), 4160-4169.

Schillinger U.; Lücke F. (1989). Antibacterial activity of Lactobacillus sake isolated from meat. Appl. Environ. Microbiol., 55: 1901-1906.

Silvetti T., Capra E., Morandi S., Cremonesi P., Decimo M., Gavazzi F., Giannico R., De Noni I., Brasca M. (2017). Microbial population profile during ripening of Protected Designation of Origin (PDO) Silter cheese, produced with and without autochthonous starter culture. LWT-Food Science and Technology, 84, 821-831.

Sonjak S., Ličen M., Frisvad J. C., Gunde-Cimerman N. (2011). The mycobiota of three dry-cured meat products from Slovenia. Food microbiology, 28(3), 373-376.

Stefanis C., Mantzourani I., Plessas S., Alexopoulos A., Galanis A., Bezirtzoglou E. (2016). Reviewing Classical and Molecular Techniques Regarding Profiling of Probiotic Character of Microorganisms. Current Research in Nutrition and Food Science Journal, 4(1), 27-47.

Sunesen L. O., Stahnke L. H. (2003). Mould starter cultures for dry sausages-selection, application and effects. Meat Science, 65(3), 935-948.

Talon R., Leroy S. (2011). Diversity and safety hazards of bacteria involved in meat fermentations. Meat science, 89(3), 303-309.

Talon R., Leroy S., Lebert I. (2007). Microbial ecosystems of traditional fermented meat products: the importance of indigenous starters. Meat Science, 77(1), 55-62. 
603 Todorov S.D. (2009). Bacteriocins from Lactobacillus plantarum production, genetic organization and 604 mode of action: produção, organização genética e modo de ação. Brazilian journal of microbiology, $605 \quad 40(2), 209-221$.

606 Visagie C.M., Houbraken J., Frisvad J.C., Hong S.B., Klaassen C.H.W., Perrone G., Seifert K.A., Varga 607 J., Yaguchi T., Samson R.A. (2014). Identification and nomenclature of the genus Penicillium. Studies 608 in Mycology, 78, 343-371.

609 Woraprayote W., Malila Y., Sorapukdee S., Swetwiwathana A., Benjakul S., Visessanguan W. (2016). 610 Bacteriocins from lactic acid bacteria and their applications in meat and meat products. Meat science, $611 \quad 120,118-132$.

612 Zhang Q.Q., Jiang M., Rui X., Li W., Chen X.H., Dong M.S. (2017). Effect of rose polyphenols on 613 oxidation, biogenic amines and microbial diversity in naturally dry fermented sausages. Food Control, $614 \quad 78,324-330$.

615 


\section{Figure legenda}

617 Table 1. Main differences between traditional and industrial fermented food products (adapted and modified 618 from El Sheikha and Montet, 2016).

619

620 Figure 1 Summary of biochemical activities performed by principal microbial groups in fermented sausages.

621 The most frequently isolated species of each group are nominated.

622 


\begin{tabular}{l|l}
\hline \multicolumn{1}{c|}{ Traditional fermented products } & \multicolumn{1}{|c}{ Industrial fermented products } \\
\hline Small-scale & Large-scale \\
Manual & Automated \\
Intensive to time & Time-sensitive \\
Possible exposure to contaminants & Minimal exposure to contaminants \\
Varying quality & Constant quality \\
Complex sensory attributes & Less complex sensory attributes \\
Attention to & Safety driven operation \\
characteristic of the product & Longer shelf-life \\
Shorter shelf-life & Reduced microbial diversity \\
Large undefined microbial diversity &
\end{tabular}

\section{Lactobacillus}

\section{L. sakei}

L. curvatus

L. plantarum

\section{Pediococcus}

P. pentosaceus

P. acidilactici

\section{Kocuria}

$K$ varians

$K$. kristinae

\section{Staphylococcus}

S. xylosus

S. simulans

S. carnosus

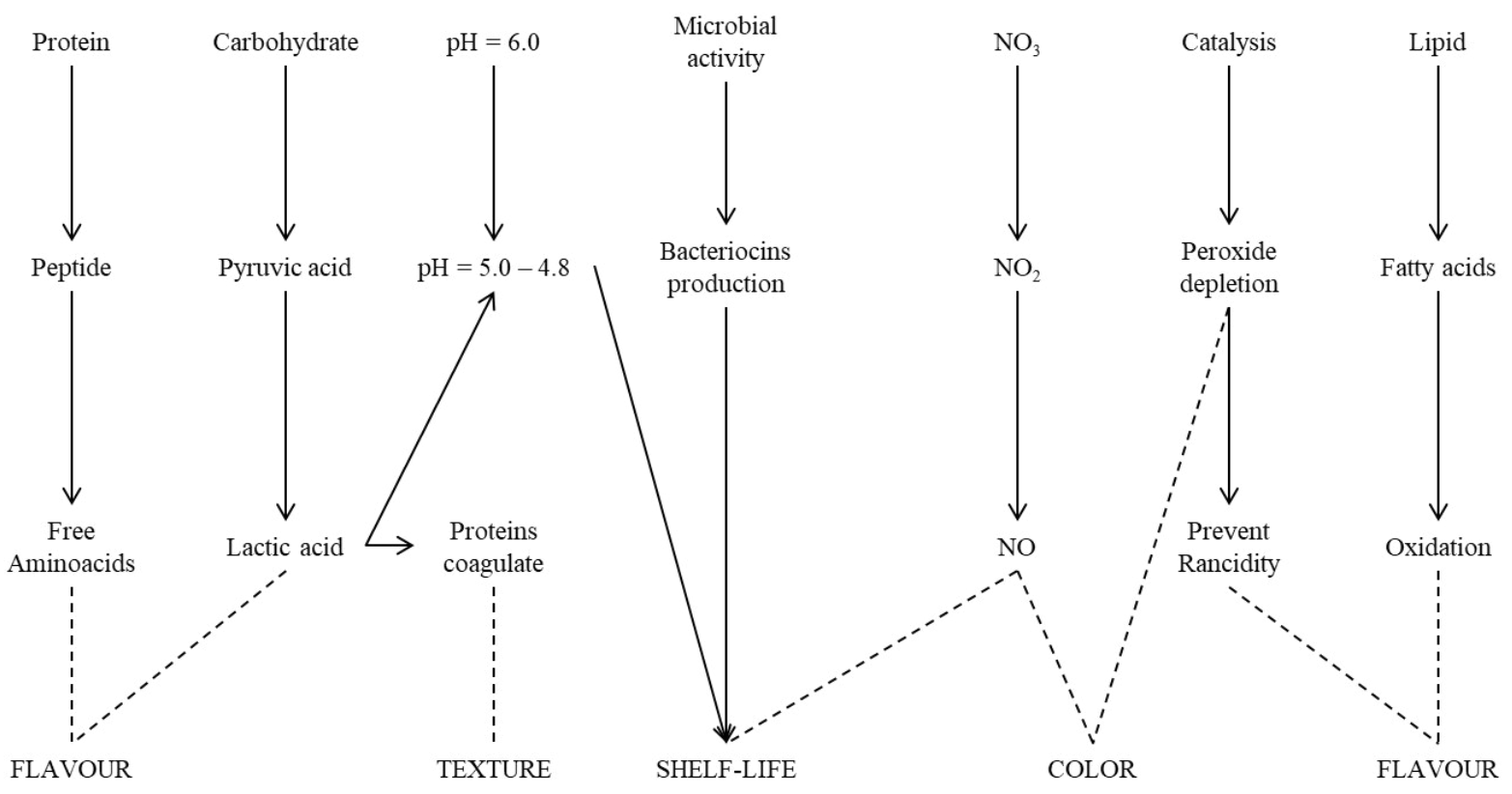

